\title{
CIRCUITO ANTIESCRAVISTA ATLÂNTICO: James Redpath e a Conferência Antiescravista de Paris, 1867
}

\author{
ATLANTIC ANTI-SLAVERY CIRCUIT: \\ James Redpath and the Anti-Slavery Conference of Paris, 1867
}

\begin{abstract}
RESUMO: Depois do fim da Guerra Civil norte-americana houve um reordenamento das posições antiescravistas no mundo atlântico. Este artigo explora as cartas sobre a escravidão brasileira do abolicionista norte-americano James Redpath e dois textos apresentados por agentes brasileiros na Conferência Antiescravista de Paris. O objetivo é demonstrar que, em ambos os casos, embora o assunto principal fosse a escravidão no Brasil, havia outros interesses coordenando essas intervenções. Isso mostra que a questão escravista era tão somente mais um elemento no tabuleiro internacional, e que qualquer análise que prescinda do contexto mais amplo corre o risco de ser incapaz de apreender os reais interesses em disputa.
\end{abstract}

PALAVRAS-CHAVE: James Redpath. Antiescravismo. British and Foreign Anti-Slavery Society

\begin{abstract}
After the end of the American Civil War there was a reordering of anti-slavery positions in the Atlantic world. This article explores the letters on Brazilian slavery of the American abolitionist James Redpath, and two texts presented by Brazilian agents at the Anti-slavery Conference in Paris. The objective is to demonstrate that in both cases, although the main issue was slavery in Brazil, there were other interests coordinating these interventions. This shows that the slave question was only one more element on the international board, and that any analysis that dispenses with the larger context runs the risk of being unable to grasp the real interests in dispute.
\end{abstract}

KEYWORDS: James Redpath. Anti-slavery. British and Foreign Anti-Slavery Society

Em meados de 1867, o The Anti-Slavery Reporter, órgão de imprensa da British and Foreign Anti-Slavery Society (BFASS) começou a republicar uma série de cartas do abolicionista norte-americano James Redpath sobre a escravidão e a vida dos escravos no Brasil. Originalmente, essas cartas foram escritas para o National Anti-Slavery Standard, um dos periódicos da American Anti-Slavery Society, entidade comandada por William Lloyd Garrison. A historiografia brasileira, salvo engano, jamais fez menção a essas missivas, embora elas marquem o início da inflexão interpretativa norte-americana a respeito da suposta suavidade da escravidão brasileira. ${ }^{134}$

Concomitantemente à republicação dessas cartas na Grã-Bretanha ocorria a Conferência Antiescravista de Paris, onde, entre outros assuntos, também estavam sendo discutidos o futuro da escravidão brasileira e a condição dos escravos no Brasil. Essa conferência foi patrocinada pela British and Foreign Anti-Slavery Society, pelo Comité Français d'Émancipation e pela Sociedad Abolicionista Española, e seu relatório foi

\footnotetext{
* Doutor em Sociologia pela Unicamp, pós-doutorando no Departamento de História da Universidade de São Paulo.

${ }^{134}$ As referências completas das cartas de Redpath são: Reporter, 1 de junho de 1867, p. 121-124; 15 de julho de 1867 , p. 161-164; 15 de outubro de 1867, p. 220-222; 15 de novembro de 1867, p. 257-261; 1 de janeiro de 1868 , p. $3-4 ; 1$ de fevereiro de 1868 , p. $28-30$. Trata-se de um material relativamente extenso, que perfaz aproximadamente 50 páginas.
} 
publicado no ano seguinte, sob o patrocínio exclusivo da BFASS. A historiografia brasileira já abordou esse relatório, mas o fez sem levar em consideração os interesses dos grupos abolicionistas que se fizeram representar na conferência.

O objetivo deste artigo é comparar esses dois materiais. A estratégia de comparação consistirá em não realizar uma análise exclusiva do teor desses documentos. Mais promissor é trabalhar com os propósitos que motivaram os autores de tais textos, o contexto político, os arranjos diplomáticos internacionais e os interesses divergentes do circuito antiescravista atlântico.

Essa estratégia permite ressaltar que tanto as cartas de Redpath quanto os textos da conferência tinham propósitos que iam muito além da crítica à escravidão brasileira ou da defesa da forma como o governo brasileiro encaminhava as medidas emancipacionistas. Embora essa afirmação pareça uma obviedade, ela não é. O movimento antiescravista, nacional ou internacional, tornou-se um movimento social e político, e ainda que suas ações tivessem o combate à escravidão como horizonte, tais ações muitas vezes tornam-se incompreensíveis se não forem inseridas no contexto que as produziu. Senão, como entender que a BFASS republicava as cartas de Redpath denunciando a severidade da escravidão brasileira ao mesmo tempo que patrocinava uma conferência na qual essa mesma escravidão era apresentada como suave, e o Brasil tomado como referência na incorporação dos negros como cidadãos? Seguramente, não se tratava de pluralidade jornalística. Havia acordos e interesses políticos, econômicos e diplomáticos que justificavam tais procedimentos; a escravidão era um elemento em disputa, mas não o único. Falar da escravidão de "outro" país podia ser uma boa maneira de intervir no seu próprio; do mesmo modo, falar da escravidão de "seu" país podia ser uma estratégia de negociação estrangeira para se alcançar outros objetivos.

As principais fontes utilizadas neste artigo são o The Anti-Slavery Reporter (doravante Reporter) e o relatório da Conferência Antiescravista de Paris. Para a reconstituição dos interesses envolvidos são utilizadas outras fontes da época, bem como a historiografia que lida com o assunto.

\section{A década antiescravista}

Os três grandes sistemas escravistas do Atlântico - Sul dos EUA, Brasil e Cuba foram desmantelados ou sofreram golpes mortais na década de 1860. Em 1862, em meio à Guerra Civil norte-americana, o presidente Abraham Lincoln assinou um tratado com a GrãBretanha para a supressão do tráfico de escravos, que ficou conhecido como LyonsSeward. Depois de décadas de recusas dos EUA em assinar qualquer tratado que concedesse poderes aos britânicos para realizar buscas em seus navios, este acordo concedeu aos signatários o direito mútuo de busca de escravos em navios suspeitos em alto mar. Embora os historiadores divirjam sobre a efetividade dessa medida, ela ajudou a consolidar o sistema de tratados anti-tráfico organizado pela Grã-Bretanha. Alguns meses depois, em meio ao conflito fratricida, Lincoln emitiu a Proclamação da Emancipação, que extinguiu a escravidão, a partir de 1 de janeiro de 1863, em todo o território da Confederação, e libertou aproximadamente quatro milhões de escravos. Com a destruição do maior sistema escravista do Novo Mundo, as autoridades e os proprietários de escravos cubanos e brasileiros perceberam que os seus sistemas logo teriam o mesmo destino (Eltis, 1987, p. 90 e 219; DRESCHER, 2011, p. 417; MARQUES, 2016, p. 244).

Os cubanos sentiram rapidamente os efeitos do Tratado Lyons-Seward, que permitiu à Grã-Bretanha realizar uma patrulha mais efetiva contra os navios negreiros na costa africana, mas principalmente ao redor de Cuba. Em 1863 e 1864, o tráfico para a ilha reduziu drasticamente, e foi extinto virtualmente em 1867. O fim da escravidão nos EUA também diminuiu o medo espanhol de que Cuba pudesse ser incorporada à União como um novo estado escravista. As propostas de reformas graduais não tardaram a aparecer. Ainda que num primeiro momento os fazendeiros cubanos tenham resistido a qualquer medida emancipacionista, a revolução anticolonialista que eclodiu na ilha em 1868, a revolução 
liberal na metrópole e a simpatia dos políticos espanhóis pelo Lincoln emancipador pavimentaram o caminho para a Lei Moret, aprovada em julho de 1870 , que garantiu às crianças nascidas de mães escravas, de 1868 em diante, a liberdade a partir dos 18 anos (SCOTT, 1991, p. 51; MONTAUD, 1990, p. 508; SCHMIDT-NOWARA, 2013, p. 142).

No Brasil, no início dos anos 1860, as autoridades acompanhavam apreensivas os desdobramentos internacionais. A "política da escravidão", montada há quase três décadas pelos saquaremas, sobrevivera à extinção do tráfico imposta pela Grã-Bretanha. Todavia, a velha Albion não parecia disposta a afrouxar sua diretriz antiescravista internacional, e sua diplomacia exigia das autoridades brasileiras uma resposta mais efetiva para a questão dos africanos livres (libertos dos navios negreiros) e dos africanos escravizados ilegalmente depois da lei de 1831. Em última instância, a diplomacia britânica utilizava todos os meios disponíveis para forçar o governo brasileiro a adotar medidas com vistas a antecipar o fim da escravidão. (PARRON, 2011, p. 17; MAMIGONIAN, 2017, p. 360).

Em janeiro de 1863, o então Ministro Plenipotenciário britânico no Rio de Janeiro, William Dougal Christie, resolveu adotar represálias contra o governo brasileiro pelo não atendimento de alguns pleitos britânicos relativamente sem importância. Nos últimos anos, a historiografia passou a associar a Guerra Civil norte-americana, principalmente a Proclamação da Emancipação de Lincoln, à decisão de Christie punir o governo brasileiro com as represálias. Embora ainda se careça de comprovações empíricas mais robustas que liguem esses episódios, é preciso reconhecer que, no quadro antiescravista internacional, essa argumentação faz sentido (PARRON, 2011, p. 322).

Todavia, talvez seja necessário prestar mais atenção aos planos (oficiais ou inoficiais) de algumas autoridades norte-americanas de transladar para o Brasil a população escrava dos EUA. Na correspondência que Christie enviou para o Foreign Office não é possível identificar nenhuma relação entre as medidas retaliatórias e a Proclamação da Emancipação. Mas, em meados de 1862, confidencialmente, o ministro britânico no Rio de Janeiro enviou ao secretário do Foreign Office uma carta relatando um plano de trazer escravos da União para o Brasil.

\begin{abstract}
Meu Senhor,
O General Webb, ministro norte-americano, tem, sem instruções, exortado veementemente o governo brasileiro a concordar em aceitar todos os escravos úteis da União, que totalizam, segundo esse cálculo, dois milhões, recebendo-os como homens livres, sujeitos a três anos de aprendizado, com a promessa de se lhes conceder terra para cada um deles no final de três anos. Ele também escreveu para seu próprio governo, recomendando este projeto.

O governo brasileiro se recusou a avaliar o projeto, mencionando como um obstáculo insuperável a sua lei de 1831 contra o tráfico de escravos, que proíbe a importação de negros libertos (Christie a Russell [confidencial], 24 de julho de 1862, p. 196-198. National Archives, F.O. 84-1180).
\end{abstract}

A historiografia há muito conhece esses planos de transplantar para o Brasil os escravos norte-americanos. Contudo, a carta de Christie a Russell, assinalada como confidencial, sugere que tais planos incomodaram a diplomacia britânica e ligaram algum sinal de alerta (LUZ, 1968, p. 49; HORNE, 2010, p. 31).

Seja como for, a partir de 1864, com a ascensão dos liberais brasileiros ao poder, começou a ser negociado um "acordo" informal entre o Brasil e a Grã-Bretanha. Esse acordo, por sua informalidade e pela diversidade de pessoas e instituições envolvidas, é bastante difícil de ser rastreado, explicitado e definido. Em linhas gerais, ele previa que o governo brasileiro encaminharia medidas emancipacionistas de modo a acelerar o fim do escravidão. Por outro lado, o Brasil pleiteava que a Grã-Bretanha revogasse a Lei Aberdeen, diminuísse suas pressões antiescravistas e a ingerência na política interna brasileira. Em 
resumo, o que os liberais pediam era um voto de confiança para que tivessem tempo de mostrar que seriam capazes de encaminhar as medidas necessárias ao combate da escravidão.

De certo modo, esse acordo foi paradoxalmente beneficiado pelo rompimento das relações diplomáticas entre os dois países, em 1863, por ocasião da "Questão Christie". Como o Brasil fortaleceu-se diplomaticamente graças ao apoio recebido de alguns países europeus que julgaram desproporcionais as represálias britânicas; e como grupos mercantis e financeiros britânicos, receosos de serem afetados economicamente pelo rompimento das relações, passaram a pressionar e criticar o seu próprio governo, os brasileiros perceberam que havia espaço político e diplomático para avançar suas reivindicações, e começaram a associar o restabelecimento das relações diplomáticas à revogação da Lei Aberdeen e à menor ingerência britânica nos negócios domésticos do Brasil (RÉ, 2018, p. 828).

É nesse momento, mais precisamente em meados de 1864, que o governo brasileiro e a BFASS estabelecem um acordo informal, no qual essa instituição atuaria pelo restabelecimento das relações entre os dois países e pela revogação do Bill Aberdeen e o Brasil encaminharia medidas emancipacionistas. Paralelamente, o governo brasileiro também começou a financiar publicações na Grã-Bretanha que difundissem uma imagem mais favorável ao Brasil, condenando o excesso das intervenções antiescravistas na política interna brasileira (Reporter, 1 de abril de 1864, p. 89-95; 1 de junho de 1864, p. 135-140; RÉ, 2019, p. 10).

O primeiro lado a dar mostra de que seguiria sua parte no acordo foi o Brasil. Em 24 de setembro de 1864, por meio do decreto 3.310, o governo de Francisco José Furtado concedia a emancipação "a todos os africanos livres existentes no Império", atendendo assim a uma das principais reivindicações da Grã-Bretanha. A BFASS, por sua vez, iniciou uma forte campanha nas duas casas parlamentares britânicas pela revogação da Lei Aberdeen e pelo restabelecimento das relações diplomáticas, e repercutiu cada um desses passos em seu periódico. O governo britânico entendeu o sinal, abrandou sua pressão antiescravista sobre o Brasil e, em 1865, tomou a iniciativa para o restabelecimento das relações entre os dois países.

Em linhas gerais, esse era o contexto de meados dos anos 1860. Naquele momento, a Guerra do Paraguai ainda havia produzido pouco efeito sobre a maneira como os norteamericanos e europeus compreendiam a situação brasileira. A rigor, até 1867, ano em que são publicadas as cartas de Redpath e ocorre a Conferência Antiescravista de Paris, as medidas para a libertação dos escravos brasileiros que se alistassem no exército foram instrumentalizadas como uma prova de que a escravidão era tão somente mais um elemento da sociedade brasileira, que poderia existir e prosperar tranquilamente sem ela.

\section{Redpath e as cartas sobre a escravidão brasileira}

James Redpath nasceu na Escócia e emigrou para os EUA em 1849, onde logo se tornou repórter do New York Tribune. Em meados da década de 1850, ele empreendeu três viagens secretas pelo Sul com o propósito de levantar depoimentos de escravos, que foram publicados em jornais abolicionistas. A compilação desse material foi posteriormente lançada em livro. No final dessa mesma década, Redpath estabeleceu contato com John Brown, o abolicionista radical da Virgínia, que o incentivou a se mudar para Boston e recrutar apoio para a insurreição escrava. Depois da derrota de Brown na revolta em Harper's Ferry e sua subsequente execução, Redpath dedicou-lhe uma biografia. O repórter também visitou o Haiti e militou pelo restabelecimento das relações desse país com os EUA. Durante a Guerra Civil, ele trabalhou como correspondente na fronteira de guerra, e depois do encerramento do conflito, foi designado como superintendente de escolas públicas na Carolina do Sul (MCKIVIGAN, 2008, p. ix; REDPATH, 1859; REDPATH, 1860; REDPATH, 1861; REDPATH, 1863).

Esse rápido perfil biográfico indica que Redpath era um abolicionista tarimbado, com vasto conhecimento do assunto e consideráveis relações políticas. Obviamente, ele acompanhou de perto os desdobramentos que se seguiram à Guerra Civil, em especial a 
disputa política dos negros pela conquista de direitos e a mais propalada que verdadeira grande migração de fazendeiros sulistas para o Brasil. Ele também transitava pelo grupo de Garrison.

Desde os anos 1830 os abolicionistas norte-americanos prestavam atenção na escravidão e nas relações raciais brasileiras descritas nos relatos de viagens e em outros materiais. Eles utilizavam esses textos como uma prova da severidade da escravidão sulista em contraposição à suposta suavidade da escravidão do império sul-americano. Do mesmo modo, tomavam como modelo de igualdade racial a ser alcançada pelos EUA as relações entre brancos, negros e mestiços brasileiros, que supostamente não impediriam que o homem de cor conquistasse qualquer posição social desde que tivesse méritos. Tratava-se, é claro, de uma leitura instrumentalizada da escravidão e das relações raciais brasileiras, cujo propósito principal era utilizá-la como modelo alternativo ao praticado naquele país e reivindicar melhorias na condição dos escravos e negros livres (CHILD, 1833, p. 8 e p. 26; AZEVEDO, 2003, p. 77).

Essa visão, entretanto, parece ter começado a ser um pouco matizada já na década de 1850, quando, diante dos projetos para transladar os negros norte-americanos para o Brasil ou de construir um império escravista que se estendesse do Sul dos EUA até a América do Sul, os abolicionistas norte-americanos expressaram o temor do surgimento de um gigante cinturão escravista continental, politicamente unificado (JOHNSON, 2013, p. 299-302; HORNE, 2010, p. 12-21).

Mas foi depois do término da Guerra Civil que os abolicionistas norte-americanos começaram decididamente a rever a compreensão que tinham da escravidão e das relações raciais no Império do Brasil. É difícil apurar tudo o que estava em questão naquele momento e a dimensão de cada fator, mas, seguramente, a ascensão e difusão das teorias cientificistas sobre a inferioridade racial dos negros e a degenerescência dos mestiços colocaram os abolicionistas em alerta. Cientistas racialistas como Samuel George Morton, Josiah Nott e Louis Agassiz tinham um público cativo (FREDRICKSON, 1971, p. 43-70; MACHADO, 2010, p. 62). Também chegavam do outro lado do Atlântico notícias sobre o descontentamento dos britânicos com os negros das Índias Ocidentais, especialmente os da Jamaica, a partir do momento em que irrompeu a rebelião de Morant Bay, em 1865. Ainda que sem poder abordar detidamente esse assunto, o que se pode dizer é que essa rebelião fez com que uma parte dos britânicos passasse a acreditar que os negros precisavam ser coagidos ao trabalho, retomando todo um debate iniciado nos anos 1850 entre Thomas Carlyle e John Stuart Mill (HUZZEY, 2012, p. 1856-186; BLABKBURN, 2013, p. 436-440; LEVY, 2002, p. 195-204).

Certo também é que entre os abolicionistas se difundiu o medo de que os sulistas emigrados para o Brasil um dia pudessem retornar ainda mais fortes aos EUA para reinstalar a escravidão. Em 1865, o New York Times ajudou a divulgar esse temor um tanto fantasioso, alegando que os sulistas deveriam voltar "comandando uma potência contra Roma". Havia ainda o medo de que o Brasil pudesse, com a ajuda dos emigrados sulistas, concorrer com o algodão dos EUA: "O Brasil, na mente dessas pessoas, tornar-se-ia não apenas um império escravocrata, desafiando os Estados Unidos na vital esfera econômica, mas também - e o que seria talvez mais perigoso a longo prazo - uma base 'contrária', de oposição, feita sob encomenda para confederados irredutíveis” (HORNE, 2010, p. 299-300).

Se antes da Guerra Civil os abolicionistas norte-americanos destacaram os aspectos menos severos da escravidão brasileira e os fatores que julgaram mais promissores para 0 desenvolvimento e a inserção social do negro, depois do conflito as preocupações se alteraram e chegara o momento de sublinhar as perversidades dessa instituição. As cartas de James Redpath devem, portanto, ser compreendidas como uma resposta a essa nova situação.

A estratégia expositiva de Redpath, conforme ele próprio reconheceu, era bastante simples. Tal como os abolicionistas anteriores, ele utilizou as narrativas de viajantes estrangeiros que visitaram o Brasil, mas antes de destacar a suposta suavidade da escravidão brasileira e as pretensas facilidades encontradas pelos negros e mestiços para 
serem incorporados à sociedade, ele salientou os infortúnios, os casos de violência, os desamparos da lei e a selvageria dos proprietários de escravos que apareceram esporadicamente nesses relatos. Na verdade, ele praticamente fez uma leitura a contrapelo das narrativas dos viajantes. Ainda que os autores destas narrativas estivessem descrevendo os aspectos considerados favoráveis ao escravo ou negro livre no Brasil, Redpath se preocupou em destacar os episódios em que a violência da escravidão conseguia prevalecer ou burlar o suposto convívio harmônico.

Em geral, suas cartas não apresentam uma argumentação linear, na qual podem ser identificados um assunto principal e sua consequente fundamentação. Elas são intensamente entremeadas com citações, cujos assuntos variam ao sabor daquilo que o autor julga conveniente destacar. Essa feição fragmentária era uma característica própria de algumas publicações antiescravistas, que visavam antes de tudo a comover o leitor. Por isso, torna-se improdutivo tentar resumir tais cartas. A melhor alternativa é empreender uma análise dos propósitos dessas cartas e sua relação com o momento histórico e as questões que aparentemente motivaram o autor a escrevê-las.

Redpath abre sua primeira carta perguntando "por quanto tempo a escravidão ainda pode durar no Novo Mundo?", e adianta que a opinião ilustrada nos EUA acredita que ela será extinta em menos de doze anos. A seguir, ele explica que também há uma opinião generalizada de que a escravidão no Brasil é mais suave do que nos estados sulistas. Todavia, assegura que com uma pequena reflexão essa "crença" se dissolverá e parará de ser difundida (Reporter, 1 de junho de 1867, p. 121).

Depois, o autor lança mão de um argumento ad hoc, ou seja, formulado a partir do próprio fato que pretendia explicar. Segundo Redpath, como há "tendências inerentes à escravidão" em todos os tempos, lugares e raças de homens, se a escravidão brasileira era, de fato, escravidão - isto é, se ela concedia ao "senhor o poder absoluto sobre o escravo negro" - "então a natureza brasileira não seria natureza humana se a posse de alguns milhões de escravos não produzisse uma abundante profusão de crueldades, sofrimentos e crimes" (Reporter, 1 de junho de 1867, p. 121).

Contraditoriamente ao seu propósito de acabar com a "crença" de que a escravidão brasileira era mais suave que a do Sul dos EUA, Redpath passa a levantar hipóteses sobre os fatores que contribuiriam para essa maior suavidade. Ele então aponta a relação da escravidão brasileira com a população, a raça e o território. Um país cuja população possui grande proporção de escravos "pode criar uma tendência [...] a fazer com que o senhor tenha medo de exercer sua terrível autoridade de maneira cruel"; ele também reconhece de imediato que a população brasileira é mestiça e, portanto, "livre dos preconceitos da cor"; por último, o "poder despótico" do senhor é diminuído num país que apresenta "oportunidades fáceis e frequentes de fuga". Como se percebe, Redpath acabou por admitir que a escravidão brasileira era mais suave, mas essa característica se devia a outros fatores, não à benignidade das leis ou dos proprietários brasileiros. Da mesma forma, ele reconheceu que a situação das pessoas de cor no Brasil era "particularmente preferível à dos EUA. Contudo, isso é uma questão, não de leis, mas de raça" (Reporter, 1 de junho de 1867, p. 121-123).

Enfim, quando Redpath saiu dos exemplos de violência extraídos das narrativas de viagem, suas explicações apresentaram uma série de contradições. Mas isso não é importante. O que é preciso reter são seus propósitos. E o principal deles era sustentar que a escravidão brasileira "não pode ser considerada mais humana do que o sistema que foi exterminado em nosso próprio país" (Reporter, 1 de fevereiro de 1868, p. 28).

Outra preocupação de Redpath era combater a noção de que o Brasil possuía leis mais favoráveis aos escravos do que os estados sulistas. Essa crítica tinha endereço preciso. Ela visava combater principalmente a obra de David Child, que, no início dos anos 1830, foi um dos principais responsáveis pela difusão dessa noção. Ao contrário de Child, Redpath discordava que leis benéficas ao escravo pudessem ser observadas num sistema escravista. $O$ poder absoluto dos senhores possibilitava que eles burlassem qualquer lei (CHILD, 1833, p. 26; Reporter, 15 de julho de 1867, p. 162). 
Em sua última carta, Redpath se preocupou em criticar o governo brasileiro por difundir informações equivocadas sobre o bom tratamento dos escravos. Ele também utilizou informação de Christie para mostrar que praticamente inexistiam esforços no Brasil para melhorar a sorte dos escravos ou encaminhar a emancipação. Ao final da carta, porém, Redpath anexou o depoimento de um "cavalheiro" identificado com o Brasil, que contradizia praticamente tudo aquilo que havia sido exposto em suas cartas anteriores e asseverava que o governo central imperial e os amigos do antiescravismo estavam se movendo para interferir na escravidão (Reporter, 1 de fevereiro de 1868, p. 30).

Em suma, o arrazoado de Redpath tinha explicitamente dois objetivos: acabar com a crença de que a escravidão brasileira era suave e mostrar que as relações raciais não eram tão favoráveis ao negro, conforme acreditavam os abolicionistas norte-americanos. Implicitamente, Redpath criticava a escravidão brasileira, negando que leis por ventura favoráveis aos escravos pudessem ser plenamente respeitadas num sistema escravista; por último, sua principal preocupação era combater a imigração de sulistas para o Brasil, por meio da difusão da noção de que a escravidão brasileira se assentava sobre outras bases, que impediriam a organização de uma forma de vida semelhante à que existira no Sul dos EUA. No fundo, seu temor era de que o Brasil passasse a representar uma grande ameaça ao mundo pós-emancipação (Reporter, 1 de fevereiro de 1868, p. 30).

As cartas de Redpath devem, portanto, ser compreendidas como resposta a uma nova situação, que se abrira com o fim da Guerra Civil e a imigração de sulistas para o Império brasileiro. Não é exagero afirmar que, ao escrever sobre a escravidão e a situação do negro no Brasil, Redpath estava mais interessado no que se passava nos EUA do que naquilo que ocorria propriamente no império sul-americano. Suas cartas tinham o objetivo de influenciar a opinião norte-americana, principalmente os sulistas que desejavam emigrar, evitando que houvesse uma transferência em massa de proprietários e que eles pudessem recriar no Brasil seus estilos de vida (SKIDMORE II, 2017, p. 13).

Já a republicação das cartas no Reporter, em Londres, foi inicialmente apenas mais um ato de troca e difusão de textos. A BFASS, desde sua fundação, adotou como estratégia coletar e difundir informações antiescravistas que lhe eram enviadas por correspondentes estrangeiros ou por entidades filiadas. Quando o Reporter começou a republicar as cartas de Redpath, ainda não se conhecia o teor completo delas. Todavia, à medida que elas foram sendo estampadas, o Comitê da BFASS, na impossibilidade e deselegância de impedir a continuidade, se viu na obrigação de alertar seus leitores para aquilo que julgava exagerado nesse material. $\mathrm{E}$, mais impressionante, especialmente quando se considera a importância internacional desta entidade, seu Comitê afirmou com todas as letras, numa espécie de advertência à penúltima carta, que acreditava na existência de uma forma suave de escravidão no Brasil.

Nós as reproduzimos [as cartas] porque achamos que elas são altamente interessantes e lançam muita luz, a partir de várias fontes, sobre o verdadeiro caráter da "instituição", num país onde tem sido frequentemente alegado que ela existe numa forma suave, como acreditamos, e com certa justificativa. Não acreditamos, entretanto, que a escravidão possa existir em qualquer país, nem em qualquer forma, sem gerar crueldade. Um abuso em si mesma, ela inevitavelmente deve engendrar abusos de todos os tipos. Todavia, quando vemos que, no Brasil, os homens mantidos como escravos não são em consequência disto e, quando livres, impedidos de ocupar cargos honrosos, e que o preconceito contra a cor, como uma simples questão de cor, não existe, somos obrigados a admitir certa modificação das circunstâncias em torno da escravidão no Brasil, que exigem reconhecimento (Reporter, 1 de janeiro de 1868, p. 3). 
Embora a BFASS estivesse preocupada com a situação dos negros emancipados dos EUA, seu Comitê julgou que aquele não era o momento de criticar a escravidão brasileira nos termos propostos por Redpath. Os interesses e planos dos abolicionistas britânicos eram outros.

\section{A Conferência Antiescravista de Paris}

Em 1865, o Reporter divulgou a criação de duas novas entidades antiescravistas europeias: a Sociedad Abolicionista Española e o Comité Français d'Emancipation. Dois anos depois, aproveitando a "Grande Exposição de Paris", as três entidades decidiram organizar conjuntamente uma conferência antiescravista internacional na mesma cidade. $O$ Programa da Conferência previa a discussão de três assuntos: o tráfico de escravos, a escravidão e os resultados da emancipação. O Reporter mencionou que o Brasil seria abordado especificamente nos dois primeiros itens. O então secretário da BFASS, Louis A. Chamerovzow, remeteu cartas para brasileiros, com o Programa da Conferência e a Convocatória para o envio de artigos, na expectativa de que "alguns notáveis" pudessem comparecer ao evento (Reporter, 2 de janeiro de 1865, p. 3; 1 de julho de 1865, p. 150; 15 de fevereiro de 1867, p. 32-35)..$^{135}$

Essa conferência é um episódio privilegiado para se perceber a miríade de interesses antiescravistas e a relação entre os abolicionistas das Américas e da Europa, formando aquilo que aqui está sendo chamado de "circuito antiescravista atlântico". Ela também permite perceber que as propostas emancipacionistas em debate no Brasil naquela época estavam igualmente sendo submetidas ao crivo da opinião pública internacional, com o objetivo tanto de selecionar aquilo que seria bem recebido pelos abolicionistas de outros países quanto de conquistar legitimidade para tais propostas.

A conferência ocorreu em 26 e 27 de agosto de 1867, dois meses depois da data prevista originalmente. Após uma rápida abertura do Presidente Edouard de Laboulaye, o então secretário francês da Conferência, Augustin Cochin, dedicou bastante atenção à escravidão brasileira, mas sua fala foi uma glosa de elementos apresentados em dois artigos dedicados exclusivamente ao Brasil. Os dois textos tinham a autoria de Ch. Quentin e do Major Taunay (Special Report..., s.d., p. 6).

Antes de abordar esses dois textos é necessário fazer uma ressalva. Sem fugir aos padrões dos eventos antiescravistas internacionais, a conferência de Paris contou com alas divergentes: uma foi representada pelas três instituições organizadoras do evento; a outra

\footnotetext{
135 Chamerovzow a Tavares Bastos, 22 de janeiro de 1867. Gaveta I-03, 31, 050. Documento 53. Divisão de Manuscritos. Biblioteca Nacional; Chamerovzow para destinatário desconhecido. Gaveta I-03, 31, 049. Documento 52. Divisão de Manuscritos. Biblioteca Nacional.
} 
por um grupo de abolicionistas radicais, comandados pelo anarquista Elisée Reclus. ${ }^{136}$ É temerário classificar os abolicionistas por sua "radicalidade", pois a BFASS em muitos momentos de sua história também foi taxada de radical, e seus membros foram chamados inclusive de idealistas irresponsáveis (TURLEY, 2013, p. 88-90). Talvez, para tentar ser mais preciso, se possa dizer que um grupo de abolicionistas presente na conferência quis emitir uma condenação mais severa à escravidão brasileira (e conseguiu seu intento); e outro grupo, representado pelas entidades organizadoras, preferiu emitir um documento mais diplomático.

A "contra-resolução" dos abolicionistas "radicais" acabou sendo publicada no relatório final da conferência. Ela fazia uma condenação explícita ao Brasil, onde quase todas as atividades estariam fundadas na escravidão. Da mesma maneira, condenava os EUA, cujas leis ainda estavam baseadas na escravidão e impediam o casamento entre pessoas de raças e cores diferentes. Por último, ela exaltava alguns abolicionistas radicais que tombaram na luta antiescravista. Impossível saber, no entanto, porque nenhuma palavra foi dita sobre a escravidão em Cuba (Special Report, s.d., p. 14).

O que, provavelmente, o grupo de abolicionistas "radicais" não sabia era que a suposta amenidade da crítica das entidades abolicionistas à escravidão e ao governo brasileiro decorria de um acordo estabelecido alguns anos antes entre agentes do governo brasileiro e o Comitê da BFASS, com vistas a facilitar o encaminhamento de medidas emancipacionistas no Brasil. Não se deve, portanto, ver nessa aparente condescendência das entidades antiescravistas europeias com o Brasil - em especial a da BFASS - qualquer proteção diferencial. ${ }^{137}$ Ao contrário, desde sua fundação, a BFASS sempre sustentou uma postura extremamente crítica em relação à escravidão brasileira. Todavia, de 1864 até aproximadamente 1869-70, essa postura foi calculadamente abrandada, na expectativa de que o governo brasileiro adotasse as medidas emancipacionistas com as quais havia se comprometido (RÉ, 2019, p. 31-32).

Conforme adiantado acima, os dois textos sobre o Brasil apresentados na conferência eram de autoria de Charles Quentin e do Major Taunay. É impossível saber o que motivou os dois autores a enviar seus trabalhos para a conferência, mas,

\footnotetext{
${ }^{136}$ Reclus foi refugiado político em Londres no início da década de 1850, depois mudou-se para uma plantation na Louisiana, fatos que podem ter contribuído para seu forte posicionamento contra a escravidão (FLEMING, 1979, p. 45).

${ }^{137}$ A historiadora Celia M. M. de Azevedo, ao analisar a "contra-resolução" dos abolicionistas "radicais", afirma que "as pressões abolicionistas internacionais contra a escravidão brasileira eram bem mais suaves e menos radicais do que aquelas dirigidas anteriormente à escravidão do sul americano" (AZEVEDO, 2003, p. 65). Essa apreciação não se aplica à BFASS nem mesmo naquele momento. Ainda que os textos da BFASS sobre a escravidão brasileira possam ser vistos como menos incisivos, eles cumpriam um determinado papel no acordo entre agentes brasileiros e essa instituição. Um claro exemplo do posicionamento severo da BFASS contra o governo brasileiro, por sua postura tímida no combate à escravidão, já pode ser visto no final dos anos 1860 , quando a BFASS tomou conhecimento dos termos do projeto que viria a se tornar a Lei do Ventre-Livre (Reporter, 1 de julho de 1869, p. 242; 30 de setembro de 1870, p. 66; 31 de dezembro de 1871, p. 212).
} 
provavelmente, se tratava de escritores dispostos a alugar sua pena. Também não é infundado supor que Quentin estava representando os pontos de vista do Partido Liberal, e Taunay, do Partido Conservador.

Quentin havia morado no Brasil, e foi professor durante seis anos no Rio de Janeiro, como ele próprio esclareceu em seu artigo. O arquivo de Tavares Bastos possui uma cópia, em francês, do trabalho que Quentin enviou à Conferência. Essa carta, entretanto, foi enviada ao liberal por Chamerovzow, o secretário da BFASS, o que demonstra que havia uma relação de proximidade entre os três, que exigia a prestação de alguma satisfação dos passos que estavam sendo tomados. Além disso, um levantamento nos arquivos diplomáticos do Itamarati constatou que Quentin recebeu subsídios do governo brasileiro, justamente na década de 1860, para escrever textos favoráveis ao Brasil - dinheiro que the era entregue diretamente pela Legação de Londres. Em 1865, por exemplo, ele lançou um opúsculo bastante severo e calunioso sobre o Paraguai, que logo foi traduzido e publicado no Rio de Janeiro - fatos que colocam em suspeição a honestidade da obra. Em 1867, também por intermédio da Legação de Londres, Quentin foi indicado para presidir a seção brasileira da Exposição Universal de Paris. Esses dados mostram uma inequívoca relação de proximidade entre Quentin e o Partido Liberal brasileiro (Special Report, s.d., 117-118; ZENHA, 2003, p. 434; Jornal do Commercio, 31 de outubro de 1867, p. 1; 8 de outubro de 1868 , p. 3). ${ }^{138}$

O texto que Quentin entregou à conferência se intitulava: "O aspecto atual e as perspectivas futuras da questão da Escravidão no Brasil”. Depois de mencionar brevemente que o tráfico de escravos desapareceu principalmente, senão exclusivamente, pelos esforços do governo, amparado pela opinião pública, Quentin foi bastante enfático: "o que queremos é a abolição e não a mitigação da escravidão". Obviamente, depois de ganhar a simpatia dos leitores, o autor foi mais generoso com os escravistas brasileiros: "sem dúvida, é um prazer pensar que as crueldades que fizeram com que os fazendeiros das Antilhas e dos EUA fossem tão tristemente celebrados nunca tenham sido praticadas no Brasil". Ele ainda acrescentou que "no Brasil, a escravidão não é uma instituição, um sistema, um dogma". Ao fazer essa distinção, a estratégia de Quentin consistia em defender que a escravidão brasileira era uma herança portuguesa, apenas tolerada, mas unanimemente condenada. Até mesmo os proprietários de escravos eram "partidários da emancipação", mas não concordavam que ela fosse realizada à suas custas: "a opinião pública exige um método que não represente a ruína dos indivíduos nem a ruína do país" (Special Report, s.d., p. 115-116).

\footnotetext{
138 Ch. Quentin a Chamerovzow, Paris, 30 de agosto de 1867. Gaveta I-03, 32, 016. Documento 16. Divisão de Manuscritos. Biblioteca Nacional. A data da carta é posterior à realização da Conferência, fato impossível de ser explicado.
} 
Em relação ao governo brasileiro, as iniciativas também eram bastante claras: "a disposição do governo pode ser atestada pelo encaminhamento ao Conselho de Estado de um esquema legislativo para a abolição da escravidão". Quentin ainda insistiu que a iniciativa das medidas era responsabilidade do governo, que deveria se adiantar às iniciativas individuais de alguns parlamentares (Special Report, s.d., p. 116-117). Esse era um ponto que vinha sendo incisivamente repisado no Brasil e no exterior. Embora qualquer parlamentar tivesse legitimidade para apresentar medidas com o objetivo de melhorar a sorte do escravo, somente o governo disporia de condições de elaborar um plano que contemplasse todos os problemas envolvidos nessa questão delicada. Essa estratégia já pode ser observada em 1865, num opúsculo publicado em Londres pelo correspondente do Jornal do Commercio, William Henry Clark ([CLARK], 1865, p. 26). Em 1867, Zacarias de Góis, o então presidente do Gabinete, se expressou quase nos mesmos termos: "O governo entendeu, pois, que devia prevenir a iniciativa individual, declarando às câmaras, ao país e ao mundo que trata deste objeto" (Anais da Câmara dos Deputados, 7 de junho de 1867, p. 66).

Na parte final de seu artigo, Quentin passou a examinar como "a emancipação será efetivada no Brasil". É impossível não se impressionar com a convicção com que ele expõe a maneira pela qual esse evento ocorrerá. É como se o futuro não estivesse mais em disputa; tudo já parecia previamente concertado, recaindo a divergência apenas sobre questões relativamente secundárias: "todos - inclusive os mais devotados partidários da abolição - rejeitam a emancipação imediata e rápida sem transição". Na sequência, ele acrescentaria: e sem indenização (Special Report, s.d., p. 118).

A questão da indenização aos proprietários é admitida por quase todos os homens no Brasil; sua posse legal foi reconhecida em todos os lugares nas colônias francesas e inglesas; e se, nos Estados Unidos, os proprietários foram despossuídos sem indenização, foi porque sua rebelião os colocou, por assim dizer, na ilegalidade. Lincoln, um ano após o começo da guerra, admitiu o direito dos proprietários a uma indenização (Special Report, s.d., p. 118).

O único problema consistia em definir como se daria essa indenização, se "em dinheiro ou em serviços a serem pagos pelos libertos". Segundo Quentin, só com muita dificuldade o Brasil conseguiria indenizar a desapropriação de quase 1.500 .000 escravos; a melhor solução seria a "indenização do proprietário por meio do serviço dos libertos". O período pelo qual o liberto serviria ao seu senhor teria ainda a "vantagem de misturar mais intimamente os dois elementos", e, para isso, contribuiria a ausência de "qualquer preconceito racial" no Brasil, onde "todos os homens livres são iguais; e essa igualdade não é apenas jurídica, ela é também de costume; é da prática diária. O liberto entra plenamente na vida política, civil e social" (Special Report, s.d., p. 118).

Já o texto do Major Taunay, intitulado "Sobre a escravidão e o tráfico de escravos no Brasil", era ainda mais conservador. ${ }^{139}$ De início, ele observou "que não era sua intenção antecipar eventos em relação à emancipação da escravidão no Brasil", mas reconheceu que os seus dias estavam contados. Para ele, a escravidão nunca "constituiu uma parte da família ou do sistema social, mas se exibiu como o lado negativo de ambos e a sua maldição". Embora os brasileiros a considerassem como um direito, o autor não tinha dúvidas de que abririam mão dela assim que a autoridade lhes ordenasse - tal como ocorreu com o tráfico (Special Report, s.d., p. 118-119).

Mas Taunay se pergunta se os proprietários não deveriam ser indenizados e se a abolição não destruiria a produção brasileira. De maneira muito próxima ao texto de Quentin, Taunay propôs que os próprios escravos indenizassem seus proprietários em forma de trabalho não-remunerado, e que o governo observasse uma "justiça rigorosa" -

\footnotetext{
139 Tratava-se, provavelmente, do major Carlos Augusto Taunay (1791-1867).
} 
obviamente, a preocupação aqui era com o suposto direito dos fazendeiros. ${ }^{140} \mathrm{Em}$ relação à segunda questão, a estratégia do autor foi mostrar que a população escrava, desde o censo de 1818, estava diminuindo ao mesmo tempo que aumentava a produção. Portanto, nada indicava que a abolição pudesse abalá-la; além disso, o aumento da população livre e as melhorias nos transportes, principalmente com a construção das ferrovias, afastavam qualquer temor de uma queda da produção brasileira. Grande parte de seu artigo é dedicada à apresentação de dados sobre a população e a produção, como se pretendesse afastar qualquer temor dos investidores estrangeiros, tanto que chegou a dizer claramente que se a abolição viesse a ocorrer, os bancos internacionais abririam seus cofres ao Brasil (Special Report, s.d., p. 119-121).

Taunay também sugeriu que não havia nenhuma "boa razão para acreditar que os escravos de hoje deixariam de trabalhar e produzir se fossem libertados amanhã". Ao contrário, a naturalização, como cidadãos, dos negros e das pessoas de cor livres, diferentemente do que ocorria em qualquer outro país, era facilitada no Brasil. Aqui o autor voltou a enfatizar um "lugar-comum" nos textos dos brasileiros ou de agentes patrocinados pelo governo brasileiro: a facilidade com que escravos e ex-escravos eram incorporados ao grêmio social, sem distinção racial. Naquele contexto, essa estratégia era uma clara tentativa de distinguir, de um lado, o Brasil, e, de outro, os EUA e a Jamaica. O drama da eliminação da escravidão, que havia começado no final da Idade Média, produzira episódios recentes e terríveis nesses dois países, que indicavam a insuficiência de apenas se substituir o trabalho escravo pelo livre: era necessário incorporar esse liberto como um igual e, nesse aspecto, o Brasil estava bem adiantado (Special Report, s.d., p. 121 e 118).

\section{Conclusão}

Um abolicionista dos EUA escreve cartas sobre a severidade da escravidão e das relações raciais no Brasil. Sua principal preocupação não é combatê-las, mas sim mudar a compreensão dos abolicionistas norte-americanos sobre elas. Em última instância, seu objetivo era desencorajar a imigração de fazendeiros sulistas para o Brasil e combater a possibilidade de que um dia eles retornassem ainda mais fortes aos EUA e reinstalassem o sistema escravista.

Essas cartas, por descuido, começaram a ser republicadas no Reporter, em Londres, mas foram desautorizadas tão logo o Comitê da BFASS se deu conta de que elas contrariavam sua diretriz antiescravista em relação ao Brasil. Essa entidade havia estabelecido um acordo com o governo brasileiro: ela militaria pelo restabelecimento das relações diplomáticas entre o Brasil e a Grã-Bretanha e pela revogação da Lei Aberdeen. Em contrapartida, o governo brasileiro se esforçaria para adotar medidas emancipacionistas. Esse acordo obrigou a BFASS a moderar sua crítica à escravidão brasileira entre os anos de 1864 a 1870, na expectativa de que a diretriz antiescravista do Estado britânico também refreasse sua pressão sobre o governo brasileiro. Sem a pressão britânica, os liberais brasileiros recém chegados ao poder poderiam convencer mais facilmente a opinião pública de que aquele era o momento de adotar as reformas. Mas essas reformas deveriam ser dosadas e implantadas sempre de acordo com as peculiaridades brasileiras.

A Conferência Antiescravista de Paris é outro evento praticamente perfeito para se ilustrar a diversidade de interesses e de propósitos por trás dos posicionamentos abolicionistas. De imediato, há divergências a respeito da resolução final do evento. Um grupo encabeçado pelas entidades organizadoras prefere adotar um tom mais diplomático e menos agressivo, ao passo que outro grupo prefere ser mais incisivo em sua condenação dos países escravistas. Todavia, esse último grupo se esquiva de fazer qualquer menção a Cuba.

\footnotetext{
140 Neste momento, o editor do relatório da conferência, Louis A. Chamerovzow, lançou duas notas de rodapé, desautorizando qualquer associação entre o texto de Taunay e as resoluções da conferência (Special Report, s.d., p. 119).
} 
Nos dois artigos específicos sobre o Brasil, percebe-se outra disputa entre os dois grandes partidos políticos brasileiros. Aparentemente, o artigo do Major Taunay apresentava um alinhamento com as posições do Partido Conservador brasileiro, reconhecia que o fim da escravidão estava próximo, mas se abstinha de comentá-lo. Os acontecimentos deveriam ser comandados pela "opinião pública". Taunay ainda pedia que houvesse uma "justiça rigorosa", ou seja, que os fazendeiros fossem indenizados pela perda de seu patrimônio. ${ }^{141}$ Chamerovzow, o secretário da BFASS e editor do relatório da conferência, ficou tão irritado com essa postura que até a criticou de maneira inusitada em notas de rodapé.

Já o artigo de Charles Quentin parecia expressar, em linhas gerais, as posições do Partido Liberal. Defendia claramente o fim da escravidão e reconhecia que as dificuldades estavam apenas nas opiniões divergentes sobre a melhor maneira de proceder. ${ }^{142}$ Ele também reconhecia que os proprietários precisavam ser indenizados pela perda de suas propriedades e, tal como Taunay, julgava que a melhor maneira de selar essa operação era libertar os escravos, mas mantê-los sob a tutela do senhor por alguns anos.

O ponto de convergência entre os dois artigos, mas de divergência com as cartas de James Redpath, era a maneira como eles julgavam peculiar e benéfica a incorporação, como cidadãos, dos negros livres ou libertos à sociedade brasileira. A historiografia já mostrou que essa estratégia foi uma decisão política tomada antes mesmo da Independência, e pode ser identificada já nas Cortes de Lisboa. A suposta facilidade com que as pessoas de cor livres se inseriam socialmente e eram reconhecidas como cidadãs perpassou incólume toda a primeira metade do século XIX e foi muito habilmente utilizada por políticos e ideólogos brasileiros ou simpáticos ao Brasil (MARQUESE e BERBEL, 2007, p. 415).

Todavia, no final da década de 1860 , quem defendia essa posição estava entrando num terreno diferente. Se nas primeiras décadas do século XIX, a defesa ou recusa da concessão da cidadania aos negros e mestiços era uma disputa eminentemente política, depois da Guerra Civil norte-americana e da rebelião de Morant Bay essas posições tinham que dialogar também com as teorias racialistas. Na década de 1860, quando os agentes brasileiros na Europa defendiam a suposta facilidade de incorporação social das pessoas de cor no Brasil, eles estavam na verdade dizendo que, diferentemente dos EUA ou das Índias Ocidentais, onde haveria uma repulsa à concessão de direitos aos negros, no império sulamericano a situação era diferente. A Grã-Bretanha poderia estar certa de que o governo brasileiro encaminharia as medidas emancipacionistas e os financiadores britânicos, tanto da dívida brasileira quanto das ferrovias, podiam ficar sossegados, pois a emancipação não significaria a ruína da economia do império, nem produziria qualquer episódio palidamente semelhante à Guerra Civil norte-americana.

Por último, a principal intenção deste artigo foi mostrar a existência de um circuito antiescravista atlântico, em que havia uma forte comunicação entre abolicionistas das Américas e da Europa. Mas tão importante quanto o reconhecimento deste circuito é a distinção dos interesses que norteavam as ações dos abolicionistas, a maneira como se

\footnotetext{
${ }^{141}$ Havia divergências entre os conservadores sobre o encaminhamento das medidas emancipacionistas. Alguns deles, como o relator do Projeto apresentado ao Conselho de Estado, Pimenta Bueno, eram favoráveis a elas. Outros, como Abaeté, Itaboraí, Eusébio de Queirós e o próprio Paranhos (que comandaria o governo em 1871, no momento de aprovação dessas medidas) pareciam querer postergá-las indefinidamente. De todo modo, o que se percebe é que havia uma posição majoritária entre os principais líderes conservadores contra o envolvimento do governo na questão escravista. Ver, por exemplo, o Parecer do Conselho de Estado Pleno, Acta de 2 de abril de 1867, em Trabalho sobre a extincção da escravatura no Brasil. Rio de Janeiro: Typographia Nacional, 1868, p. 19 e segs.

142 Novamente, tal como se pode observar entre os conservadores, não havia consenso no Partido Liberal sobre a viabilidade e a oportunidade do encaminhamento das medidas emancipacionistas. O Marquês de Olinda, por exemplo, era terminantemente contrário a elas. Por outro lado, alguns epígonos deste partido, como Nabuco de Araújo, Souza Franco e Zacarias Góis eram favoráveis à adoção de medidas antiescravistas depois do término da Guerra do Paraguai. Jequitinhonha defendia a adoção imediata. De todo modo, o que se pode afirmar com alguma segurança é que havia uma posição majoritária entre os liberais favorável à implantação destas medidas tão logo houvesse oportunidade. Ver Trabalho sobre a extincção da escravatura no Brasil, p. 19 e segs.
} 
articulavam política e ideologicamente, as inúmeras posturas divergentes e a defesa de posições em que o combate da escravidão, embora sempre estivesse no horizonte, não necessariamente estava desvinculado de outras causas, que podiam tomar a precedência.

\section{Referências bibliográficas}

\section{Fontes}

Anais da Câmara dos Deputados

Biblioteca Nacional. Divisão de Manuscritos

Jornal do Commercio

National Archives, Serie F.O. 84

The Anti-Slavery Reporter

\section{Outros materiais}

CHILD, David L. The despotism of freedom; or the tyranny and cruelty of American Republican slave-masters, shown to be the worst in the world; in a speech, delivered at the first anniversary of the New England Anti-Slavery Society, 1833. Boston: The Boston Young Men's Anti-Slavery Association, for the Diffusion of Truth, 1833.

[CLARK, William Henry]. The relations of the British and Brazilian governments. London: Chapman and Hall, 1865.

REDPATH, James. A guide to Hayti. New York: G. Woolworth Colton, 1861.

REDPATH, James. The public life of Capt. John Brown. Boston: Thayer and Eldridge, 1860.

REDPATH, James. The roving editor: or, talks with slaves in the Southern States. New York: A. B. Burdick, 1859.

REDPATH, James. Toussaint L'Ouverture. A biography and autobiography. Boston: James Redpath, publisher, 1863.

Special report of the Anti-Slavery Conference, held in Paris, in the Salle Hers, on the twentysixth and twenty-seventh August, 1867. London: Committee of the British and Foreign AntiSlavery Society, s.d.

Trabalho sobre a extincção da escravatura no Brasil. Rio de Janeiro: Typographia Nacional, 1868.

\section{Historiografia}

AZEVEDO, Celia Maria Marinho de. Abolicionismo. Estados Unidos e Brasil, uma história comparada (século XIX). São Paulo: Annablume, 2003

BLACKBURN, Robin. The American Crucible. Slavery, Emancipation and Human Rights. London: Verso, 2013.

DRESCHER, Seymour. Abolição. Uma história da escravidão e do antiescravismo. São Paulo: Editora Unesp, 2011.

ELTIS, David. Economic growth and the end of the transatlantic slave trade. New York: Oxford University Press, 1987.

FLEMING, Marie. The anarchist way to socialism. Elisée Reclus and nineteenth-century European anarchism. London: Croom Helm, 1979. 
FREDRICKSON, George M. The black image in the White mind. The debate on AfroAmerican character and destiny, 1817-1914. Middletow: Wesleyan University Press, 1971.

GOLDBERG, David Theo. Liberalism's limits: Carlyle and Mill on "The Negro Question". In: WARD, Julie; LOTT, Tommy (ed.). Philosophers on race. Critical Essays. Oxford: Blackwell Publishing, 2002, p. 195-204.

HORNE, Gerald. O Sul mais distante. Os Estados Unidos, o Brasil e o tráfico de escravos africanos. São Paulo: Companhia das Letras, 2010.

HUZZEY, Richard. Freedom burning. Anti-slavery and empire in Victorian Britain. Ithaca: Cornell University Press, 2012.

JOHNSON, Walter. River of dark dreams. Slavery and empire in the cotton kingdom. Cambridge: Harvard University Press, 2013.

LEVY, David M. How the Dismal Science got its name. Classical economics and the ur-text of racial politics. Ann Arbor: University of Michigan Press, 2002.

LUZ, Nicia Vilela. A Amazônia para os negros americanos. (As origens de uma controvérsia internacional). Rio de Janeiro: Saga, 1968.

MACHADO, Maria Helena P. T. O Brasil no olhar de William James. Cartas, diários e desenhos, 1865-1866. São Paulo: Edusp, 2010.

MAMIGONIAN, Beatriz G. Africanos livres. A abolição do tráfico de escravos no Brasil. São Paulo: Companhia das Letras, 2017.

MARQUES, Leonardo. The United States and the transatlantic slave trade to the Americas, 1776-1867. New Haven: Yale, 2016.

MARQUESE, Rafael de Bivar; BERBEL, Márcia Regina. The absence of race: slavery, citizenship, and pro-slavery ideology in the Cortes of Lisbon and the Rio de Janeiro Constituent Assembly (1821-4). Social History, v. 32, 2007, p. 415-33.

MCKIVIGAN, John. Forgotten firebrand. James Redpath and the making of NineteenthCentury America. Ithaca: Cornell University Press, 2008.

MONTAUD, Inés Roldán. Los partidos políticos y la polémica abolicionista tras la paz del Zanjon. In: SOLANO, Francisco de; GUIMERÁ, Agustín. Esclavitud y Derechos Humanos. La lucha por la libertad del negro en el siglo XIX. Madri: CSIC, 1990.

PARRON, Tâmis. A política da escravidão no Império do Brasil, 1826-1865. Rio de Janeiro: Civilização Brasileira, 2011.

RÉ, Henrique Antonio. A revogação do Bill Aberdeen e a Lei do Ventre Livre: um acordo antiescravista internacional, 1864-1872. Revista de História, n. 178, 2019, p. 1-34.

RÉ, Henrique Antonio. Um agente do Império brasileiro em Londres: William Henry Clark e o fim da política da escravidão saquarema. Antíteses, v. 11, n. 22, p. 815-840, jul./dez. 2018.

SCHMIDT-NOWARA, Christopher. Anti-slavery in Spain and its colonies, 1808-86. In: MULLIGAN, William; BRIC, Maurice (eds.). A global history of anti-slavery politics in the nineteenth-century. New York: Palgrave Macmillan, 2013, p. 137-148.

SCOTT, Rebecca J. Emancipação escrava em Cuba. A transição para o trabalho livre, 18601899. Rio de Janeiro; Campinas: Paz e Terra; Editora da Universidade Estadual de Campinas, 1991.

SKIDMORE II, William E. 'A milder type of bondage': Brazilian slavery and race relations in the eyes of American abolitionists, 1812-1888. Slavery \& Abolition, 2017.

TURLEY, David. Anti-slavery activists and officials: "influence", lobbying and the slave trade, 1807-1850. In: HAMILTON, Keith \& SALMON, Patrick. Slavery, diplomacy and empire. 
Britain and the suppression of the slave trade, 1807-1975. Londres: Sussex Academic Press, 2013.

ZENHA, Celeste. Imagens do Brasil civilizado na imprensa internacional: Estratégias do Estado Imperial. Cadernos do CHDD, ano I. o 2. Brasília, DF: Fundação Alexandre de Gusmão. Centro de História e Documentação Diplomática, 2003, p. 423-438.

Recebido em julho de 2018. Aprovado em dezembro de 2018. 